\title{
A door to be kept open
} Broad sanctions that could isolate Indian and Pakistani scientists from the West are a counter-productive
response to the two nations' unwelcome arrival in the nuclear club. Sanctions should be used with care.

S cientists in India and Pakistan have reacted indignantly to the discovery that some of their collaborations with international partners may be coming to an abrupt end. This is a result of sanctions imposed by the United States and others in the aftermath of the nuclear weapons tests conducted by both nations in May. They are entitled to be upset. But they can hardly be surprised. After all, international non-proliferation efforts that have sought with some success to restrict the spread of nuclear weapons are based on the concept that defiance should be punished. It is hard to see how such efforts can maintain any credibility if no punishment is now forthcoming.

Despite India's protestations (see page 513), the Western response so far has been relatively limited. The US government is only withdrawing funds from collaborations with agencies directly involved in the nuclear weapons and ballistic missiles programmes of both countries (India is the chief target, as such work had already ended under earlier economic sanctions against Pakistan). In some cases, the target of such sanctions is legitimate. But these agencies are also involved in many branches of research that have nothing to do with nuclear weapons or missiles.

The human cost of such actions can be considerable, even if they do not mark the end of scientific collaboration between the United States and the sub-continent. The State Department is showing some discretion; the law that automatically triggered sanctions when the Indian tests took place could be interpreted more harshly, requiring an end to all US-supported scientific collaboration. Amid allegations of a clampdown on all scientists from the sub-continent seeking visas to travel to the United States, the State Department says that it is working out a new policy on the circumstances in which these can be issued.

As they do so, however, department officials should ask them- selves who benefits from the curtailment of scientific contact or collaboration between India and Pakistan and the West. Such curtailment will do little to slow down the clandestine weapons programme of either country. But it will worsen the isolation of both at a time when greater engagement with the outside world is the best available hedge against a potentially cataclysmic military confrontation between them. Indeed the clearest beneficiary, perhaps, is the nationalist government of India, which started the whole crisis in the first place and would reap crude political gains from any moves to isolate Indian science and marginalize its scientists.

This contradiction affects not only scientific sanctions but all the others which the United States has put in place. The imposition of sanctions by the world's largest economy on the world's largest democracy was always likely to expose the limitations of such a strategy as an instrument of foreign policy. Indeed the US Congress has already admitted as much, exempting massive grain sales from the sanctions in order to please American farmers. The realization that the most economically significant sanctions cannot survive poses a new danger: that effective sanctions will be allowed to lapse, leaving in place a series of token measures, of which the restriction of scientific collaboration could well be one. That would be a ridiculous outcome.

Scientific collaboration between the Indian subcontinent and the West is an essential line of communication that both sides must now fight to preserve. At the very least, the National Academy of Sciences and the US scientific societies should press the State Department to maintain normal scientific relations as far as is possible within the letter of the sanctions law and, in particular, to maintain the right of scientists from the two countries to travel freely. Even non-proliferation efforts would benefit.

\section{The right man in the right place}

\section{Japan's choice of Akito Arima as its new minister of education is to be welcomed.}

n recent days, the eyes of the world have focused on the finance minister chosen by Japan's new prime minister, Keizo Obuchi, to try to pull Japan — and Asia — out of recession. But Obuchi's bold selection of reformist Akito Arima to head the conservative Ministry of Education, Science, Sports and Culture (Monbusho) is more likely to have a dramatic impact on Japan's long-term future - if his government stays in power long enough.

It is ironic that Arima, who recently served as president the Institute of Physical and Chemical Research (RIKEN), should be chosen. In 1991, when president of Tokyo University, Arima took the then minister of education, Yutaka Inoue, on a tour of the university's dilapidated science buildings, and won an apology from the minister for the sorry state of affairs. Now Arima has his own opportunity to bring about some real change.

Arima has championed the introduction of external reviews to assess research at universities and research institutes in Japan. He won new funds for renovating university infrastructure, and was a key player behind the 1996 Basic Science and Technology Law, which has created a healthier environment for the funding of science in general. With his additional experience on government advisory committees, no one could be better qualified.

Hopefully, Arima will use his new post to push through a more widespread use of research assessment in Japan's university system, which has been resisting the introduction of such objective measures. But care must be taken to introduce sophisticated and fair means of assessment, rather than the simplistic measures of paper output that Arima has used in the past to sell the need for more evaluation.

Arima could also benefit Japan's universities profoundly if he could solve their chronic shortage of technicians. And his experience at RIKEN, under the Science and Technology Agency, makes him well qualified to take charge of the planned merger of the agency and the ministry of education. But it will require clever manoeuvring to ensure that Japan's science ends up better off as a whole, and that support for the pursuit of knowledge for its own sake in existing centres of excellence does not suffer at a time when so much emphasis is being placed on science's contribution to socioeconomic gain. 